\title{
EVALUATION OF THE PROPHYLACTIC AND THERAPEUTIC ROLE OF BONE MARROW MESENCHYMAL STEM CELLS INJECTION ON THE AFFECTED TONGUE OF 5- FLUOROURACIL TREATED RATS
}

\author{
Asmaa S. Elgamal *
}

\begin{abstract}
Objectives: Chemotherapy induced stomatitis is considered one of the challenging factors that affect chemotherapy treatment coarse. So, this study was conducted to evaluate the possible role of intravenous injection of mesenchymal bone marrow stem cells (MBMSCs) in preventing or ameliorating the side effects of chemotherapy on the rat's tongue.
\end{abstract}

Methods: 40 rats were divided into: (G1): normal control group, $(\mathrm{G} 2)$ : chemotherapy group; injected with chemotherapy, (G3): prophylactic group; injected with chemotherapy and treated with stem cells before chemotherapy, (G4): therapeutic group; injected with chemotherapy then treated with stem cells. At day 8 all animals were sacrificed, the tongue was dissected. Examination of the dorsal and ventral surfaces of the tongue in addition to tongue muscles was performed.

Results: Only therapeutic gr. showed marked improvement of chemotherapy induced stomatitis which was manifested by increased epithelial thickness with numerous rete pigs, increased filliform papillae and increased mucosal proliferation rate. But chemotherapy induced muscle atrophy showed no improvement in both treated groups.

Conclusion: injection of MBMSCs has a therapeutic effect on chemotherapy induced mucosal atrophy. Also it was approved that, within a period of 8 days, stem cells have neither prophylactic nor therapeutic effect on chemotherapy induced lingual muscle atrophy.

KEY WORDS: Bone marrow mesenchymal stem cells, chemotherapy induced mucosal atrophy, chemotherapy induced muscle atrophy, chemotherapy induced stomatitis, oral mucositis and intravenous stem cells injection.

* Lecturer, Oral Biology Department, Faculty of Dentistry, Beni Suef University, Egypt. 


\section{INTRODUCTION}

The treatment of malignant tumors usually involves chemotherapy, radiotherapy or surgery (either as a single therapy or in combination $)^{[1]}$.

Most of chemotherapeutic drugs work by impairing mitosis. They prevent mitosis by damaging DNA or inhibiting the cellular organelles involved in cell division. The chemotherapeutic agents are classified according to their mechanism of action into: Alkylating agents, Anti-metabolites, Anti-microtubule agents, Topoisomerase inhibitors and finally Cytotoxic antibiotics ${ }^{[2-4]}$.

5-Fluorouracil is one of Anti-metabolites group; Fluorouracil is a nucleobase analogue (to the pyrimidine uracil) that is metabolized in the cell to form at least two active products; 5 fluourouridine monophosphate (FUMP) and 5-fluoro-2'-deoxyuridine 5'-phosphate (fdUMP). FUMP becomes incorporated into RNA and fdUMP inhibits the thymidylate synthase enzyme; both of which lead to arresting the cells in S phase and cell death $^{[4,5]}$.

As chemotherapy affects cell division, tumors with high growth rates are more sensitive to chemotherapy; as larger proportion of the targeted cells are undergoing cell divisions at any time. While malignancies with slower growth rate tend to respond to chemotherapy much more modestly ${ }^{[5]}$.

Many of chemotherapy side effects are due to their damage to rapidly dividing normal cells as well as their damage to rapidly dividing tumor cells. These normal cells such as bone marrow, digestive tract and hair follicle cells are sensitive to antimitotic drugs. This results in the most common side-effects of chemotherapy as myelosuppression, mucositis ${ }^{[6,7]}$, infertility ${ }^{[8]}$, alopecia ${ }^{[9,10]}$, peripheral neuropathy ${ }^{[11]}$ and cachexia ${ }^{[12]}$.

Cancer cachexia is a syndrome of weight loss that results from depletion of skeletal muscle mass. The skeletal muscle atrophy in cancer cachexia is due to systemic inflammation arising from both cancer cells and cancer treatment ${ }^{[13]}$.
Oral mucositis is an inflammatory painful condition occurs in $40 \%$ of patients receiving chemotherapy, $60 \%$ of patients receiving radiotherapy and $92 \%$ of patients receiving both chemotherapy and radiotherapy ${ }^{[14]}$. Clinically, oral mucositis is manifested by mouth, throat, and abdominal pain, bloating, nausea, vomiting, and severe diarrhea. These manifestations lead to a prolonged hospital stay, an increased need for antibiotics, narcotic analgesia and parenteral nutrition. More importantly, mucositis threatens the efficacy of cancer treatment due to interruption of chemotherapy cycle and dose deescalation, thus adversely affecting patient survival and quality of life ${ }^{[15]}$.

Histopathological evaluation of mucositis lesion shows mucosal thinning caused by apoptosis and depletion of the epithelial basal layer. It's begin in the epithelium but then progress to involve the connective tissue ${ }^{[16]}$. The therapeutic potential of bone marrow mesenchymal stem cells (BMMSCs) has obviously been brought into spotlights in treatment of soft tissue injury as treatment of chronic wounds ${ }^{[17]}$, accelerate wound healing ${ }^{[18]}$, radiation-induced intestinal injury prevention [19], ulcer closure ${ }^{[20]}$ in addition to skeletal muscular atrophy treatment ${ }^{[21]}$. So, the present work was designed to explore the histological effect of intravenous injection of BM- MSCs on the affected tongue of chemotherapy treated rats (when they are injected before and after chemotherapy). Also, this study investigated the effect of this therapy on the mucosal proliferative capacity through expression of anti-PCNA antibody and the degree of lingual muscle atrophy repair by Masson Trichrom stain under the same experimental conditions.

\section{MATERIALS AND METHODS}

Samples: 40 male Wister rats weighting around 200 grams were used in the present study. Rats were housed in wire mesh cages (4 rats / cage) under controlled temperature and good ventilation. All rats were fed on standardized laboratory balanced diet. All Institutional and National Guidelines for the care and use of animals were followed. 
Stem cells: BM-MSCs used in this study were purchased from biochemistry department in faculty of medicine Cairo University. For tracking the stem cells, they were prelabeled with PKH26 dye that is a red fluorescent linker dye binds to the cell membrane of stem cells. This dye is ideal for in vitro and in vivo cell tracking as it is stable and divides equally when the cells divide.

Dose: The animals were intravenously injected with a single dose of $1.5 \times 10^{(6)}$ cells/ body at tail vein ${ }^{[22]}$.

Chemotherapy: Intraperitoneal injection of $100 \mathrm{mg} / \mathrm{kg} 5$-Fluorouracil (5-fu) was performed at the $1^{\text {st }}$ day of the experiment followed by injection of $65 \mathrm{mg} / \mathrm{kg}$ at the $3^{\text {rd }}$ day which is a dose sufficient to induce oral mucositis [23].

Grouping the animals: 10 rats were served as a control group $(\mathrm{G} 1)$, the remaining 30 rats received intraperitoneal injection of $5-\mathrm{fu}$ at the $1^{\text {st }}$ and $3^{\text {rd }}$ day of the experiment according to the mentioned dose. Then they were equally divided into 3 groups; (G2) chemotherapy gr.: injected with 5-florouracil only, (G3) prophylactic gr.: injected with stem cells just before the $1^{\text {st }}$ dose of 5 -fu injection and (G4) therapeutic gr.: injected with stem cells after the last dose of 5 -fu (at the $4^{\text {th }}$ day).

Samples collection and processing: At day 8, all animals were scarified by overdose of sodium thiopental. The tongue was dissected, fixed in $10 \%$ buffered formalin. Sections of 4-6 $\mu$ thickness were prepared; unstained sections were used for florescent microscope examination. The other sections were processed for routeine $\mathrm{H} \& \mathrm{E}$ stain, Masson trichrome stain and Immunohistochemical examination using Proliferating Cell Nuclear Antigen (PCNA).

Digital Image Analysis: All slides were digitized using Olympus digital camera installed on Olympus microscope with photo adaptor. The resulted images were analyzed on Intel Core based computer using Video Test Morphology software (Russia). The ventral epithelial thickness of H\&E stained specimens was measured using magnification of
400 , the percentage of +ve PCNA reaction (brown colored) was performed using a magnification of 400 with frame area 786432 and finally in Masson Trichrome stained slides, magnification of 100 with frame area $1.09 \mathrm{e}+007$ were used.

Statistical analysis: All data were tabulated and statistically analyzed by SPSS (statistical package for social science) software using one sample $T$ test to measure the means and slandered deviation of each group and Paired sample T test to compare between all groups.

\section{RESULTS}

\section{a- Histological Results}

\section{$H \& E$ stain:}

Tongue papillae; in control gr., the filliform papillae were tall, numerous, with pointed tip and have thick epithelium and keratin layer. In contrast, the papillae of chemotherapy gr. were either few in number or have rounded tip, their epithelium were thinner with desquamated keratin layer also vaculations were observed in the basal and suprabasal layer. In prophylactic gr., they were slightly irregular in shape with varying thickness while in therapeutic gr. they were numerous, thick with pointed tip (fig. 1). Fungiform papillae were obviously observed in G1 with well-formed $2^{\text {ry }}$ papillae. They were rarely seen in G2 and if so, they lack their $2^{\text {ry }}$ papillae. They started to be noticed again in G4 followed by G3 but their $2^{\text {ry }}$ papillae were small in some cases (fig. 2).

Ventral surface of the tongue: In G1, the ventral surface revealed normal stratified squamous epithelium with an average thickness 1047.5 $\pm 163 \mu$ While G2 showed very thin epithelium $(227.6 \pm 41.2 \mu)$ with nearly absence of rete pigs, the keratin layer was very thin and desquamated. Also most of G3 specimens showed thin epithelium $(338.2 \pm 91.9 \mu)$ in contrast to G4 which revealed thick epithelium $(947.4 \pm 66.5 \mu)$ with marked rete pigs and thick keratin layer in most of specimens 
(fig. 3). The statistical analysis revealed no significant difference between the control group and the therapeutic group (P value was 0.106) but there was a significant difference between the control gr. and prophylactic gr. (P value was 0.000) (table 1).
The lamina propria of the ventral mucosa showed normal blood vessels (bl. vs.) in G1. While in G2, followed by G3, the blood vessels (bl. vs.) were severely dilated and congested. In G4, the bl. vs. were moderately dilated but not congested (fig. 3).

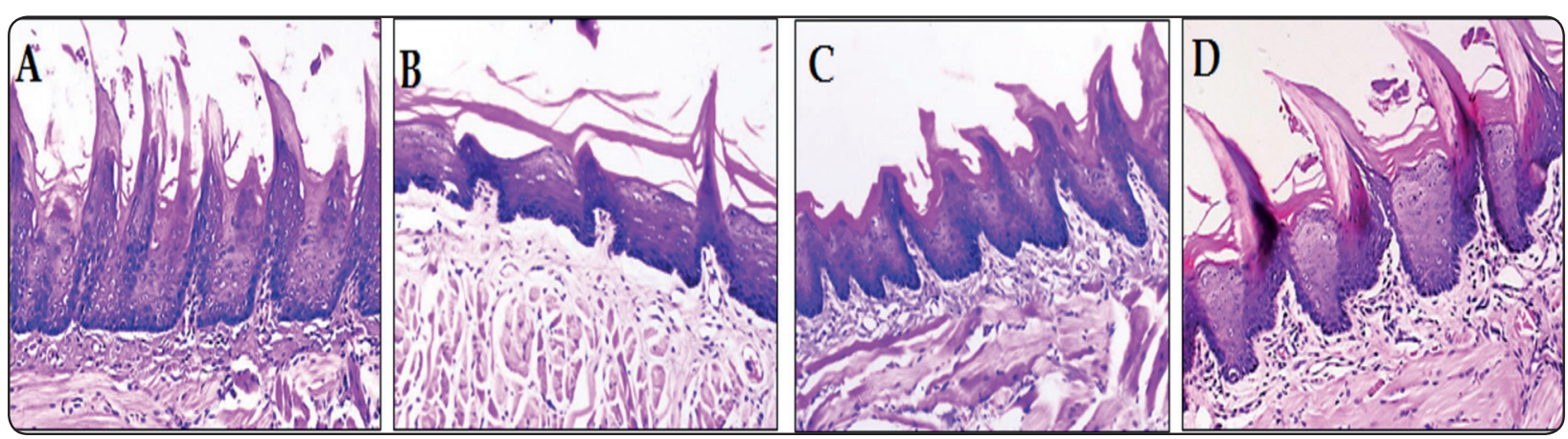

Fig. (1), Photomicrograph demonstrates shapes of filliform papillae; (A) control gr., (B) chemotherapy gr., (C) prophylactic gr. and (D) therapeutic gr. (H\&E x200).

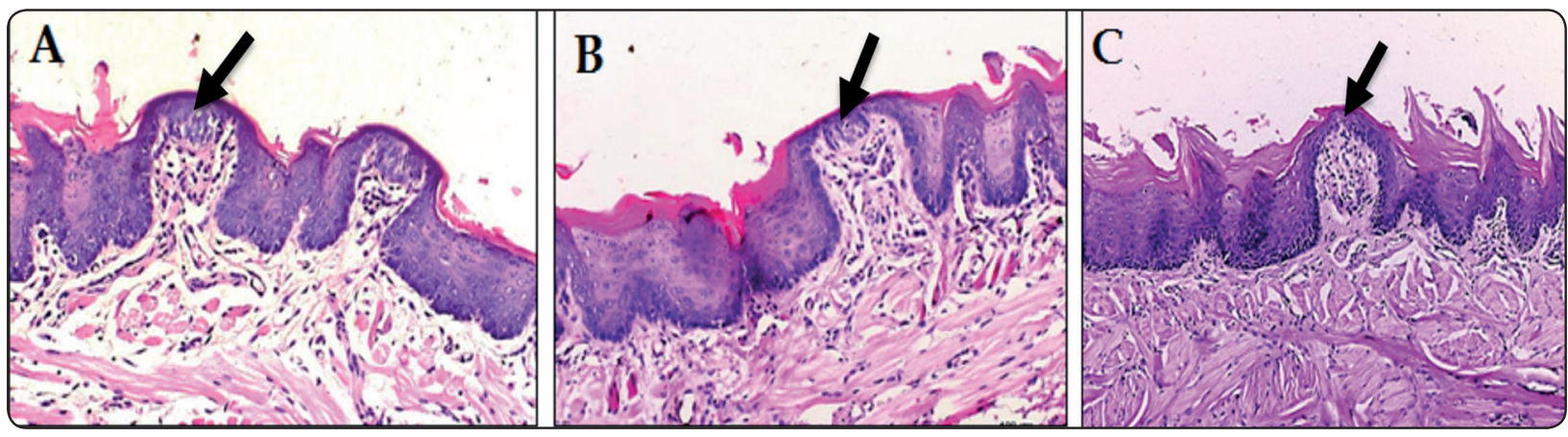

Fig. (2), Photomicrograph demonstrates the shape of fungiform papillae in all groups; (A) well formed 2ry papillae seen in control gr. (B) rudimentary 2ry papillae seen in therapeutic and prophylactic gr. and (C) no 2ry papillae which rarely seen in chemotherapy gr. (H\&E x200).

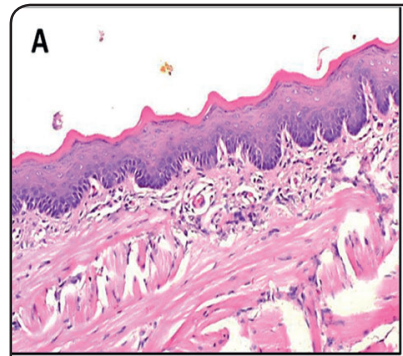

(A) Control gr.

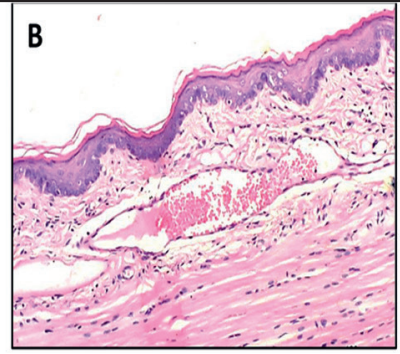

(B) Chemotherapy gr.

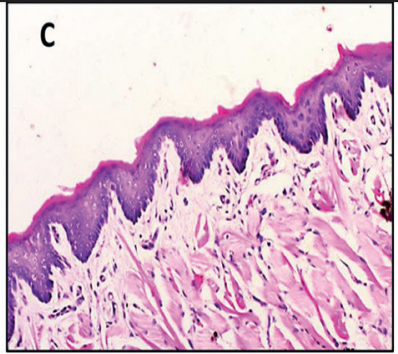

(C) Prophylactic gr.

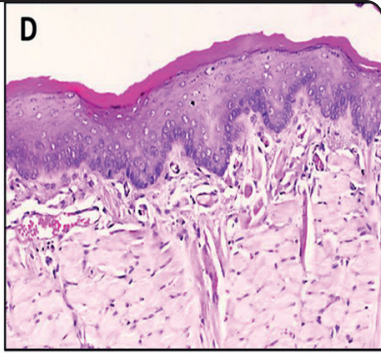

(D) Therapeutic gr.

Fig.(3); (3A-D) Photomicrograph demonstrates mucosa of the ventral surface of the tongue; . (H\&E x200). 


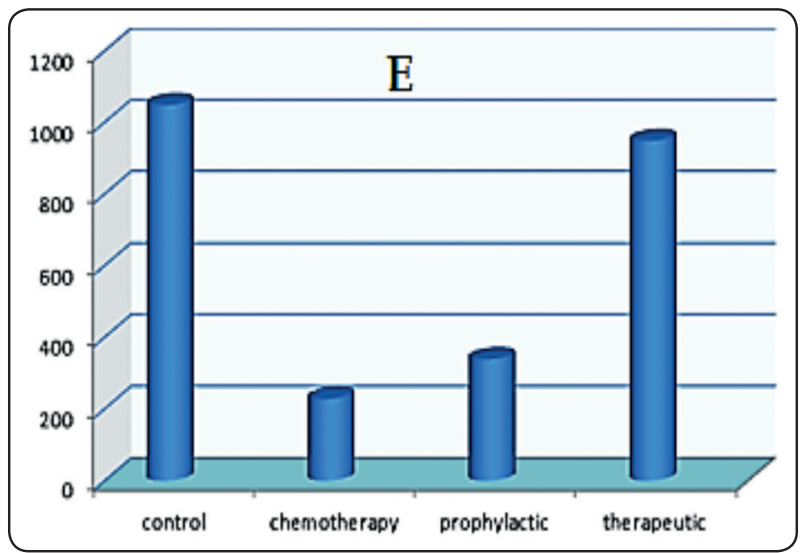

Fig. (3E): Diagram showing the difference between epithelium thicknesses of each group in microns.

TABLE (1) Paired Samples Test compares between the epithelium thicknesses

\begin{tabular}{|c|c|c|c|c|c|c|c|c|c|}
\hline & \multicolumn{5}{|c|}{ Paired Differences } & \multirow{3}{*}{$\mathrm{T}$} & \multirow{3}{*}{ df } & \multirow{3}{*}{$\begin{array}{c}\text { Sig. } \\
\text { (2-tailed) }\end{array}$} \\
\hline & & \multirow{2}{*}{ Mean } & \multirow{2}{*}{$\begin{array}{c}\text { Std. } \\
\text { Deviation }\end{array}$} & \multirow{2}{*}{$\begin{array}{l}\text { Std. Error } \\
\text { Mean }\end{array}$} & \multicolumn{2}{|c|}{$\begin{array}{l}\text { 95\% Confidence Interval of } \\
\text { the Difference }\end{array}$} & & & \\
\hline & & & & & Lower & Upper & & & \\
\hline Pair 1 & $\begin{array}{c}\text { Control - } \\
\text { chemotherapy }\end{array}$ & 819.84000 & 178.10704 & 56.32239 & 692.42990 & 947.25010 & 14.556 & 9 & .000 \\
\hline Pair 2 & $\begin{array}{l}\text { Control - } \\
\text { prophylactic }\end{array}$ & 709.26100 & 215.65805 & 68.19706 & 554.98852 & 863.53348 & 10.400 & 9 & .000 \\
\hline Pair 3 & $\begin{array}{l}\text { Control - } \\
\text { therapeutic }\end{array}$ & 100.01400 & 176.21027 & 55.72258 & -26.03924 & 226.06724 & 1.795 & 9 & .106 \\
\hline Pair 4 & $\begin{array}{l}\text { Chemotherapy } \\
\text { - prophylactic }\end{array}$ & -110.57900 & 117.52853 & 37.16579 & -194.65385 & -26.50415 & -2.975 & 9 & .016 \\
\hline Pair 5 & $\begin{array}{l}\text { Chemotherapy } \\
\text { - therapeutic }\end{array}$ & -719.82600 & 80.66592 & 25.50880 & -777.53093 & -662.12107 & -28.219 & 9 & .000 \\
\hline Pair 6 & $\begin{array}{l}\text { Prophylactic - } \\
\text { therapeutic }\end{array}$ & -609.24700 & 113.16057 & 35.78451 & -690.19720 & -528.29680 & -17.025 & 9 & .000 \\
\hline
\end{tabular}

The lingual Muscle: routeine examination of G1 revealed normal skeletal muscle fibers with normal size, peripherally located nucleus and mild macrophages infiltration (fig. 4A, 4B). All the specimens in G2 and most of G3 and G4 showed different signs of muscle atrophy and degeneration as fatty degeneration, moderate to severe macrophages infiltration and shrinkage of muscle fibers in addition to presence of oedema and dilated congested blood vessels (fig. 4C, 4D, 4E, 4F). 

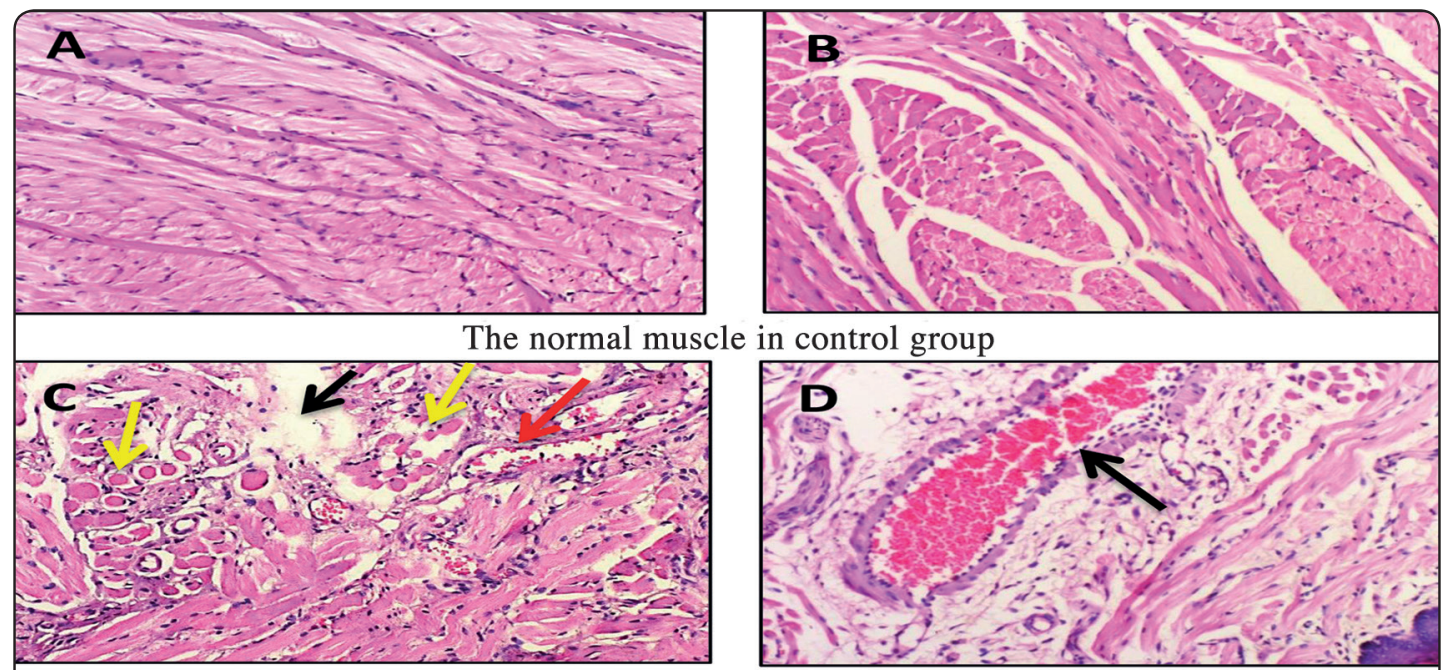

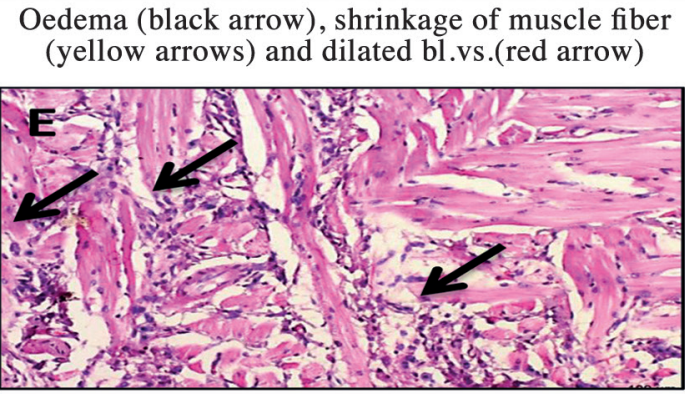

Increased c.t. fibers, macrophages and inflammatory cells (black arrows)

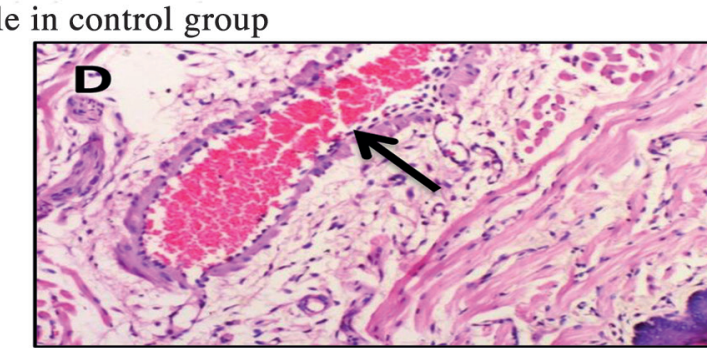

Congested bl. Vs. (black arrow)

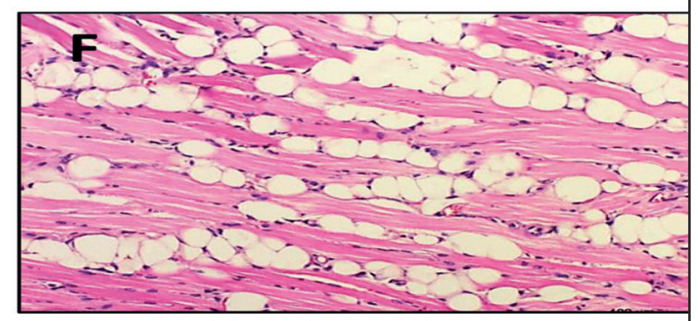

Fatty degeneration

Fig.(4) Photomicrograph showing the lingual muscle in all groups (H\&E x 200).

Masson trichrome stain: The muscles of tongue tip, tongue core and the submucosal muscle of the dorsal surface of the tongue were examined. In $\mathrm{G} 1$, the tip of the tongue and the tongue core revealed increased collagen fibers in between the muscle bundles more than the submucosal muscle of the dorsal surface of the tongue which appeared tightly packed together with minimal amount of collagen fibers in between (fig 5A, 5C and 5E), in all other groups treated with chemotherapy (G2, G3 and G4), the muscle fibers appeared smaller in size with increased collagen fibers in between them more than the control group. Also, densely packed irregular collagen fibers were increased obviously between the muscle bundles even in the submucosal muscle of the dorsal surface (fig 5B, 5D and 5F). The statistical analysis revealed that, the muscle fibers of the control group represented $(41.9 \pm 2.5 \%)$ of the specimen. While in treated groups represented; $(25.7 \pm 3.8 \%)$ in chemotherapy gr., $(25.2 \pm 5.8 \%)$ in prophylactic gr., $(28.3 \pm 7.9 \%)$ in therapeutic gr. (fig. $5 \mathrm{G})$. There was a statistical significant difference between the control group and chemotherapy gr. (Pvalue 0.000) but there was no significant difference between chemotherapy gr. and prophylactic gr. ( $\mathrm{P}$ value 0.828 ) or therapeutic gr. (P value 0.316 ) (table 2). 


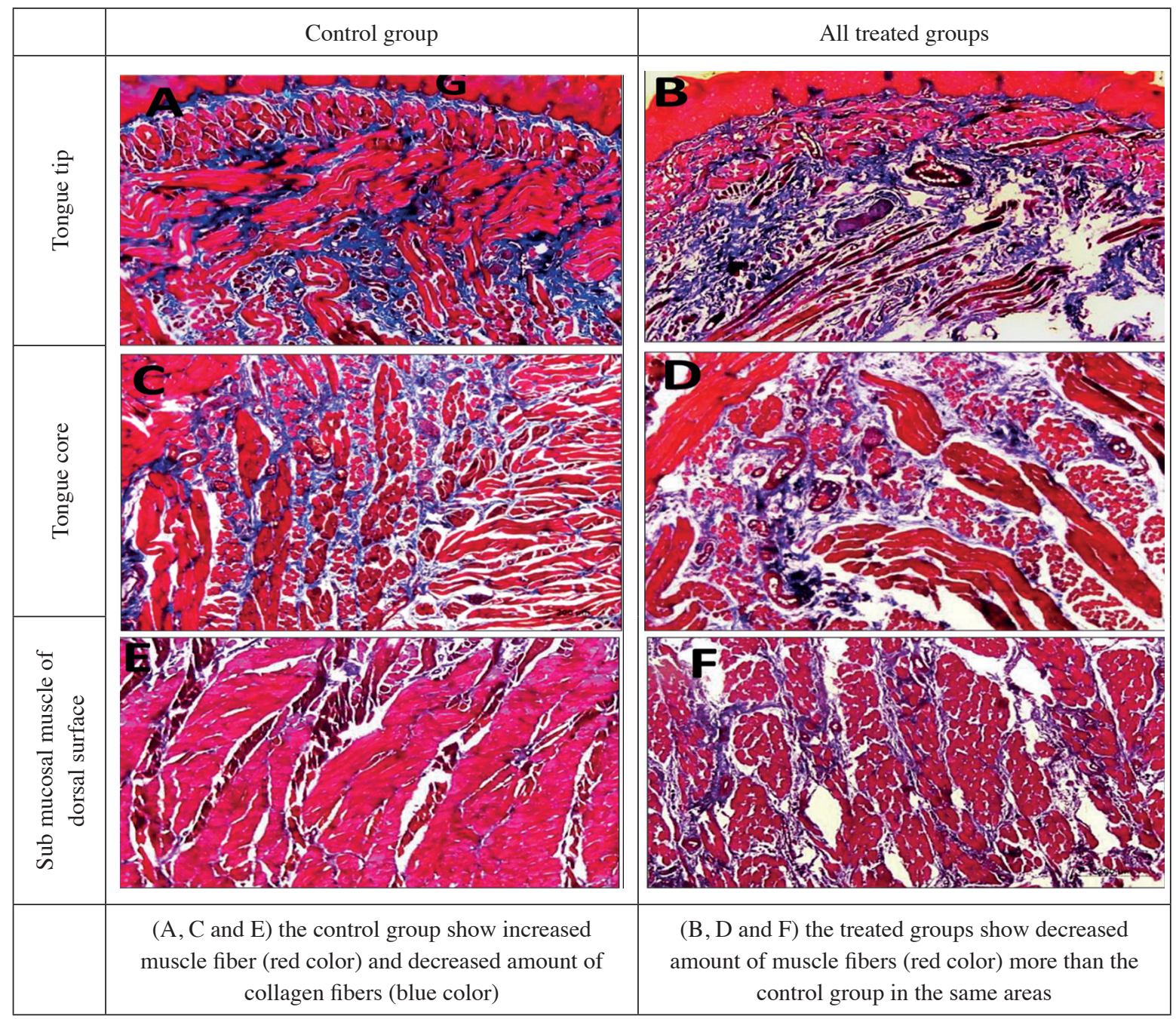

Fig. (5); (5A-F)Photomicrograph showing the lingual muscle stained by Masson Trichrome in all groups (M.T. x 100).

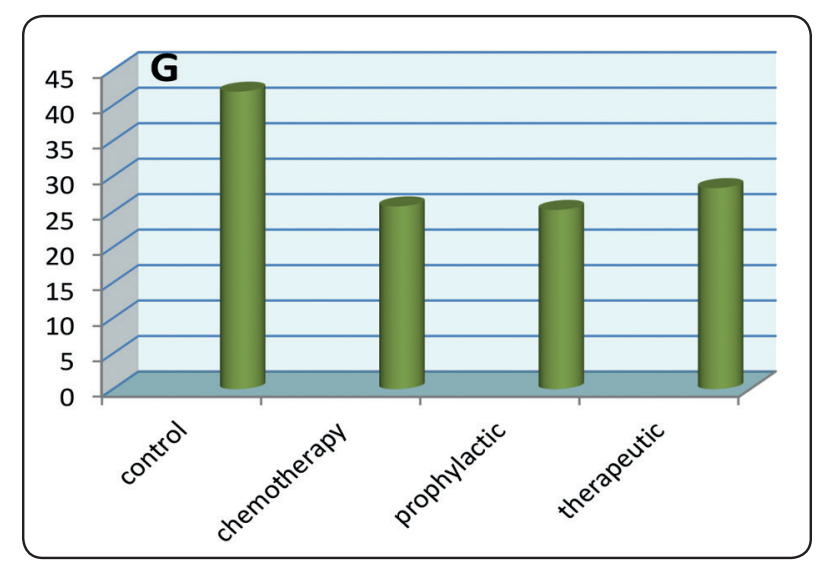

Fig. (5G): Diagram showing the difference between muscle fiber stained by Masson Trichrom of each group. 
TABLE (2), Paired Samples Test compares between muscle fiber from Masson Trichrom stain of all groups.

\begin{tabular}{|c|c|c|c|c|c|c|c|c|c|}
\hline & \multicolumn{5}{|c|}{ Paired Differences } & \multirow{3}{*}{$\mathrm{T}$} & \multirow{3}{*}{ df } & \multirow{3}{*}{$\begin{array}{c}\text { Sig. } \\
\text { (2-tailed) }\end{array}$} \\
\hline & & \multirow[t]{2}{*}{ Mean } & \multirow[t]{2}{*}{$\begin{array}{c}\text { Std. } \\
\text { Deviation }\end{array}$} & \multirow[t]{2}{*}{$\begin{array}{l}\text { Std. Error } \\
\text { Mean }\end{array}$} & \multicolumn{2}{|c|}{$\begin{array}{c}95 \% \text { Confidence Interval of } \\
\text { the Difference }\end{array}$} & & & \\
\hline & & & & & Lower & Upper & & & \\
\hline Pair 1 & $\begin{array}{l}\text { control - } \\
\text { chemotherapy }\end{array}$ & 5.86926 & 6.15802 & 1.85602 & 11.98239 & 20.37961 & 8.718 & 9 & .000 \\
\hline Pair 2 & $\begin{array}{l}\text { control - } \\
\text { prophylactic }\end{array}$ & 6.58997 & 6.31548 & 2.08393 & 11.95682 & 21.38518 & 8.000 & 9 & .000 \\
\hline Pair 3 & $\begin{array}{l}\text { control - } \\
\text { therapeutic }\end{array}$ & 9.18399 & 9.20754 & 2.90423 & 6.97617 & 20.11583 & 4.664 & 9 & .001 \\
\hline Pair 4 & $\begin{array}{l}\text { chemotherapy } \\
\text { - prophylactic }\end{array}$ & 6.92606 & 7.40619 & 2.19021 & -4.46460 & 5.44460 & .224 & 9 & .828 \\
\hline Pair 5 & $\begin{array}{l}\text { chemotherapy } \\
\text { - therapeutic }\end{array}$ & 7.84200 & 9.22586 & 2.47986 & -8.24483 & 2.97483 & -1.063 & 9 & .316 \\
\hline Pair 6 & $\begin{array}{l}\text { prophylactic - } \\
\text { therapeutic }\end{array}$ & 11.08108 & 10.83854 & 3.50415 & -11.05193 & 4.80193 & -.892 & 9 & .396 \\
\hline
\end{tabular}

\section{b- Immunohistochemical results:}

Examination of PCNA immunolocalization sections revealed strong +ve reaction in the epithelium of control and therapeutic groups while weak reaction was observed in chemotherapy and prophylactic groups (fig. 6). The statistical analysis revealed the mean values of the expressed PCNA reaction were: $(12.8+1.9 \%)$ in control group, $(2.9+1.2 \%)$ in chemotherapy gr., $(2.6+0.9 \%)$ in

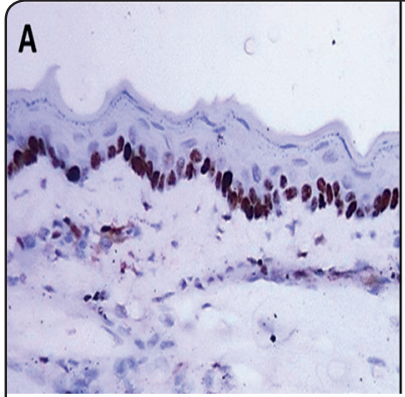

(A) Control gr.

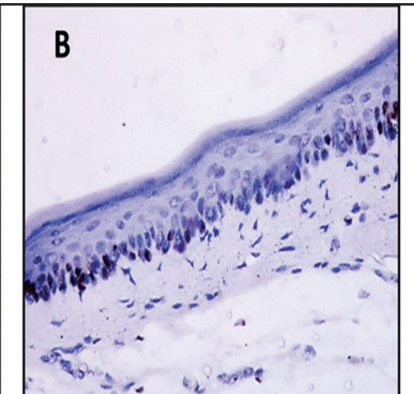

(B) Chemotherapy gr.

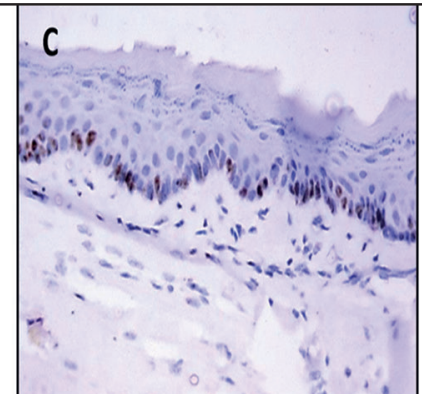

(C) Prophylactic gr.

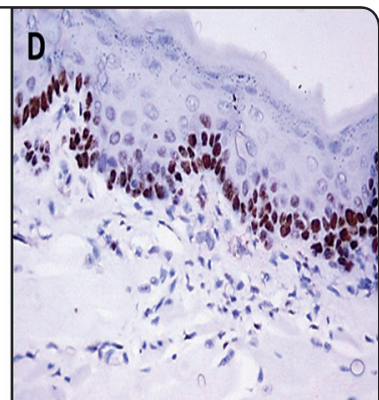

(D) Therapeutic gr.

Fig.(6); (6A- D) Photomicrograph demonstrates the intensity of PCNA expression in each group;(PCNA x 400). 


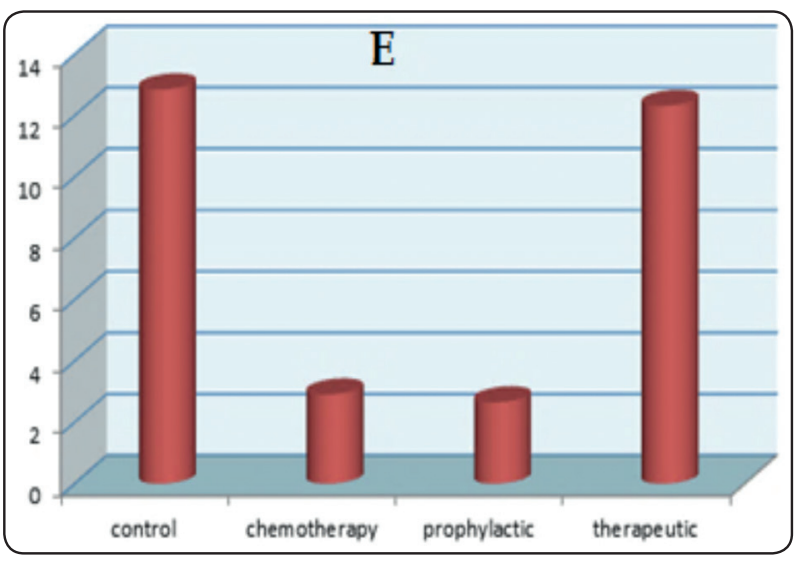

Fig. (6E): Diagram showing the differences between PCNA immunoexpression in each group.

\section{c- Florescent microscope results:}

Examination of therapeutic group showed increased number of stem cells aggregates labeled with PKH 26 in the tongue indicating successful homing of stem cells to the affected area. Stem cells also were observed in the prophylactic group also but with lesser degree.

\section{d- Statistical result:}

The statistical analysis are summarized in tables $1: 3$.

TABLE (3) Paired Samples Test compares between PCNA immunoexpression of all groups.

\begin{tabular}{|c|c|c|c|c|c|c|c|c|c|}
\hline & \multicolumn{5}{|c|}{ Paired Differences } & \multirow{3}{*}{$\mathrm{T}$} & \multirow{3}{*}{ df } & \multirow{3}{*}{$\begin{array}{c}\text { Sig. } \\
\text { (2-tailed) }\end{array}$} \\
\hline & & \multirow[t]{2}{*}{ Mean } & \multirow[t]{2}{*}{$\begin{array}{c}\text { Std. } \\
\text { Deviation }\end{array}$} & \multirow[t]{2}{*}{$\begin{array}{l}\text { Std. Error } \\
\text { Mean }\end{array}$} & \multicolumn{2}{|c|}{$\begin{array}{l}95 \% \text { Confidence Interval of } \\
\text { the Difference }\end{array}$} & & & \\
\hline & & & & & Lower & Upper & & & \\
\hline Pair 1 & $\begin{array}{l}\text { control - } \\
\text { chemotherapy }\end{array}$ & 9.94400 & 2.58451 & .81730 & 8.09515 & 11.79285 & 12.167 & 9 & .000 \\
\hline Pair 2 & $\begin{array}{l}\text { control - } \\
\text { prophylactic }\end{array}$ & 10.20000 & 1.71027 & .54083 & 8.97655 & 11.42345 & 18.860 & 9 & .000 \\
\hline Pair 3 & $\begin{array}{l}\text { control - } \\
\text { therapeutic }\end{array}$ & .53200 & 4.77964 & 1.51146 & -2.88715 & 3.95115 & .352 & 9 & .733 \\
\hline Pair 4 & $\begin{array}{l}\text { chemotherapy } \\
\text { - prophylactic }\end{array}$ & .25600 & 1.78834 & .56552 & -1.02330 & 1.53530 & .453 & 9 & .661 \\
\hline Pair 5 & $\begin{array}{l}\text { chemotherapy } \\
\text { - therapeutic }\end{array}$ & -9.41200 & 2.59632 & .82103 & -11.26929 & -7.55471 & -11.464 & 9 & .000 \\
\hline Pair 6 & $\begin{array}{l}\text { prophylactic - } \\
\text { therapeutic }\end{array}$ & -9.66800 & 3.83409 & 1.71466 & -14.42865 & -4.90735 & -5.638 & 9 & .005 \\
\hline
\end{tabular}

\section{DISCUSSION}

A previous studies was performed using a model of chemotherapy-induced stomatitis described by Sonis et al, (1990) which depends on chemotherapy administration and mechanical irritation of buccal mucosa to produce clear clinical ulcers and inflammatory condition ${ }^{[24]}$.

In the current work, we performed another model of mucositis by injection of 5-FU only to focus on its cytotoxic effect on the rats tongue without additional mechanical irritation. This model was performed by several authors ${ }^{[22,25]}$. The animals in the present study were scarified at day 8 (which is the $5^{\text {th }}$ day after the $2^{\text {nd }}$ dose of chemotherapy) as it is known that typical signs of chemotherapy induced mucositis start from the $2^{\text {nd }}$ day of injection and reach to the maximum at the $5^{\text {th }}$ day then start to recover ${ }^{[26]}$. 
The tongue was the tissue of choice for the current study as it has different points of interest concerning chemotherapy cytotoxicity; the lingual muscle which is definitely affected by chemotherapy as any skeletal muscle ${ }^{[13]}$, the mucosa of the ventral surface which is very sensitive to chemotherapy [1] and finally the papillae on the dorsal surface which is more resistant to chemotherapy in low doses ${ }^{[27]}$.

The intravenous routee of stem cells injection of was chosen in the current work to evaluate their migration ability to injured sites after transplantation. Also, it is considered the least invasive technique and has multiple systemic effects that lead to treatment of several diseases, in different organs, induced by chemotherapeutic drug. There are many scientists also used intravenous injection of stem cells in treatment of different diseases as Zhange et al. (2012) ${ }^{[22]}$. For their tracking, stem cells were prelabeled with PKH26 fluorescent linker dye which was successful and aggregates of florescent stem cells appeared in all specimens of G3 and G4 which indicates the ability of stem cells to migrate and home in the injured tissue after chemotherapy injection. Succeful migration of stem cells after intravenous injection was observed in several

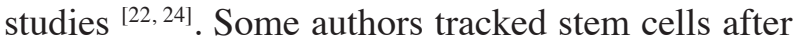
systemic injection and found marked decrease in stem cells concentration in the affected tissue by time as González et al.(2009) who observed that the rapid migration of stem cells to the inflamed colon in rats was followed by gradual decrease by time which reached to minimum at day $8{ }^{[28]}$. Also Toma et al. (2009) found that after 3 days from intraarterial infusion of MSCs, the number of MSCs decreased to $14 \%$ of the initial number because of cell death in situ ${ }^{[29]}$. This decrease in number exactly happened in our experiment, the early injected stem cells (in prophylactic gr.) were observed to be less in number than the latterly injected cells (therapeutic gr.) at the time of scarification. This may explain why the stem cells didn't give a satisfactory improvement as a prophylactic treatment for stomatitis in the present study.
It is well known that the ventral surface of the tongue is more sensitive to the 5-FU than the dorsal surface with no apparent ulceration on both surfaces [30]. This exactly found in G2 in our study as the decreased epithelial thickness and congested blood vessels were markedly observed in the ventral surface than the dorsal surface and no ulceration was observed in both surfaces.

The marked epithelial atrophy in G2 coincides with other studies that investigated the effect of 5-fu on different mucosal type as Von Bültzingslöwen et al. (2001) who investigated its effect on the oral epithelium of rats ${ }^{[31]}$ and Gawish et al. (2013) who investigated its effect on the rats small intestine ${ }^{[32]}$. All of them found marked decrease in epithelial thickness after injection. In addition, Vanhoecke et al. (2015) stated that a single dose of $150 \mathrm{mg}$ $5 \mathrm{FU} / \mathrm{kg}$ showed decreased oral epithelial thickness between 2 and $12 \mathrm{hr}$ post-5FU treatment, Clear signs of apoptosis were observed at $12 \mathrm{hr}$ and no sign of ulcerations were observed at the level of the tongue ${ }^{[30]}$.

In the present study, the dorsal surface of the tongue also was affected by 5 -fu which is manifested by atrophy of filliform and fungiform papillae. This is confirmed by Bertolini et al. (2017) study as they mentioned that both route of administration of 5-FU (intravenous and intraperitoneal) led to epithelial atrophy and filliform papillae affection especially with I.V. routee ${ }^{[27]}$. It was noticed that fungiform papillae (which contain taste buds and their receptors) were nearly absent in G2 and this was explained by Comeau, et al. (2001) who reported that 5-fluorouracil is one of antineoplastic drugs that have been associated with taste dysfunction. As these drugs are designed to target rapidly dividing cancer cells and, unfortunately, rapidly dividing cells in the body including taste receptors which proliferate every 10 days ${ }^{[33]}$.

Concerning oral stomatitis in the present study, both ventral and dorsal surface of the tongue showed better improvement in G4 than other treated groups 
(G2 and G3). This improvement is represented by significant increase in epithelial thickness than G2 and G3, significant increase in the proliferation rate than $\mathrm{G} 2$ and $\mathrm{G} 3$, decreased congested blood vessels, increased number and sharpness of filliform papillae and finally reappearance of fungiform papillae. This result coincide with Zhange et al. (2012) who evaluated the effect gingival mesenchymal stem cells (GMSCs) and found a significant reduction of mucositis on the dorsal surface of the tongue at day $9^{[22]}$. Many authors regarded the therapeutic effect of stem cells to their secretion of cytokines, chemokines and growth factors which lead to stimulation of angiogenesis, suppression of inflammation, inhibition of apoptosis and enhancement of endogenous repair by stimulating intrinsic stem and progenitor cell proliferation ${ }^{[34,35]}$.

Guo et al. (2013) regarded the anti-inflammatory role of MSCs transplantation to reduction of gene expression of the inflammatory cytokines TNF $\alpha$, IL-1 $\beta$ \& IL-6 ${ }^{[36]}$. Hendijani (2015) reported that, MSCs mitigate oral and GIT mucositis by enhancing angiogenesis and improving resistance to oxidative stress induced apoptosis. In addition, MSC administration led to faster recovery from myelosuppression by providing an excellent supportive environment for hematopoiesis ${ }^{[37]}$.

The H\&E lingual muscle examination of G1 revealed presence of mild macrophages infiltration which is considered a consistent feature of skeletal muscle and these cells may increase dramatically after injury especially at day 3 and started to decrease by day $6^{[38]}$.

It is well known that chemotherapy administration leads to cachexia which is manifested by increased muscle macrophages, signs of degeneration and atrophy and these singes were exactly observed in G2. Braun et al. (2014) found in his study that chemotherapy administration resulted in a significant loss of skeletal muscle mass 18 hours after administration. He regarded this muscle atrophy to rapid inflammatory response after administra- tion of chemotherapy which drives activation of the hypothalamic-pituitary-adrenal axis that increases the circulating level of corticosterone, the predominant endogenous glucocorticoid in rodents ${ }^{[13]}$.

In the current work, the improvement of skeletal muscle atrophy in G3 and G4 wasn't satisfactory. As all signs of degeneration in G2 also observed in the treated groups and the muscle loss was significantly different between the control group and all other treated group. This coincide with some authors tried to transplant satellite cells by injection into the affected muscle but it was with no clinical benefits and they reported that the problem appears to be in the need for massive numbers of injections due to rapid loss of satellite cells distributed at local injection sites ${ }^{[39]}$. This finding also was explained by Coletti (2018) who reported that chemotherapy induces Nf-KB expression which is sufficient to trigger muscle wasting. Taken together these findings in addition, the fact that NF-kB targets not only muscle fibers but also muscle stem cells suggests that chemotherapy may damage multiple targets ${ }^{[40]}$.

The time and route of stem cells administration also may have a significant role in success of muscle regeneration; the time needed for muscle regeneration is more than the time needed for epithelial regeneration because of the high turnover of epithelial cells. Koponen et al. (2007) found that umbilical cord stem cells transplantation leads to muscle regeneration after 3 weeks in Ischemic muscles in rats ${ }^{[41]}$. Also Aboushady et., al, (2012) found that subcautenouslly injected MSCs leads to lingual muscle regeneration after 2 weeks from radiotherapy induced stomatitis in rats ${ }^{[42]}$. For all these reasons, MSCs injection approved to have no preventive effect on the skeletal muscle atrophy induced by chemotherapy in our study. But more experiments are needed with more extended time and dose adjustment to investigate whether they have a therapeutic effect on muscle atrophy or not. 
Finally, in the current work, it was observed that stem cells have no prophylactic effect either on chemotherapy induced stomatitis or muscle atrophy. This may be due to their direct exposure to cytotoxic effect of chemotherapy unlike the stem cells of therapeutic group which are injected after several days of chemotherapy injection. This result is confirmed by Somaiah et al. (2018) who found that treatment with chemotherapeutic drugs resulted in functional defects in MSC which is manifested by reduced proliferation, osteogenic and adipogenic differentiation. He found also, the drug treated MSC also showed decreased expression of cell surface receptors, and the changes in proliferation, phenotype and differentiation were partially reversible after withdrawing the drugs from the cells ${ }^{[43]}$.

\section{CONCLUSION}

From the present study it was found that treatment with intravenous injection of MBMSCs after chemotherapy administration reduces the severity of mucositis of rats tongue, but stem cells have no prophylactic role when they are injected before chemotherapy administration. Also it was approved that, within a period of 8 days, stem cells have neither prophylactic nor therapeutic effect on chemotherapy induced lingual muscle atrophy.

\section{REFERENCES}

1. Al Refai AS. E ffects of Kurdistan Honey on the Tongue of Chemotherapy Treated Albino Rats (Immunohistochemical Study). J Cytol Histol. 2014;05(06). doi:10.4172/21577099.1000272

2. Minotti G, Menna P, Salvatorelli E, Cairo G, Gianni L. Anthracyclines: Molecular advances and pharmacologie developments in antitumor activity and cardiotoxicity. Pharmacol Rev. 2004;56(2):185-229. doi:10.1124/pr.56.2.6

3. Parker WB. Enzymology of purine and pyrimidine antimetabolites used in the treatment of cancer. Chem Rev. 2009;109(7):2880-2893. doi:10.1021/cr900028p

4. Focaccetti C, Bruno A, Magnani E, et al. Effects of 5-fluorouracil on morphology, cell cycle, proliferation, apoptosis, autophagy and ros production in endothelial cells and cardiomyocytes. Wang Y-J, ed. PLoS One. 2015;10(2):e0115686. doi:10.1371/journal.pone.0115686

5. Corrie PG. Cytotoxic chemotherapy: clinical aspects. Medicine (Baltimore). 2008;36(1):24-28. doi:10.1016/j. mpmed.2007.10.012

6. Gibson RJ, Keefe DMK. Cancer chemotherapy-induced diarrhoea and constipation: Mechanisms of damage and prevention strategies. Support Care Cancer. 2006;14(9):890900. doi:10.1007/s00520-006-0040-y

7. Davila ML. Neutropenic enterocolitis. Curr Treat Options Gastroenterol. 2006;9(3):249-255. doi:10.1007/s11938006-0043-2

8. Brydøy M, Fosså SD, Dahl O, Bjøro T. Gonadal dysfunction and fertility problems in cancer survivors. Acta Oncol (Madr). 2007;46(4):480-489.doi:10.1080/02841860601166958

9. Chadha V, Shenoi S. Hair loss in cancer chemotherapeutic patients. Indian J Dermatol Venereol Leprol. 2003;69(2):131132. http://www.ijdvl.com/article.asp?issn=0378-6323; yea $\mathrm{r}=2003$; volume $=69$; issue $=2$; spage $=131$; epage $=132$; aulast $=$ Chadha. Accessed December 19, 2019.

10. Chon SY, Champion RW, Geddes ER, Rashid RM. Chemotherapy-induced alopecia. J Am Acad Dermatol. 2012;67(1). doi:10.1016/j.jaad.2011.02.026

11. Grisold W, Oberndorfer S, ... AW-A of N, 2011 U. Chemotherapy and polyneuropathies. kup.at. https://www.kup.at/ journals/abbildungen/gross/16526.html. Accessed December 19,2019

12. Wang H, Li TL, Hsia S, Su IL, Chan YL, Wu CJ. Skeletal muscle atrophy is attenuated in tumor-bearing mice under chemotherapy by treatment with fish oil and selenium. Oncotarget. 2015;6(10):7758-7773. doi:10.18632/oncotarget.3483

13. Braun TP, Szumowski M, Levasseur PR, et al. Muscle atrophy in response to cytotoxic chemotherapy is dependent on intact glucocorticoid signaling in skeletal muscle. PLoS One. 2014;9(9). doi:10.1371/journal.pone.0106489

14. Elting LS, Cooksley C, Chambers M, Cantor SB, Manzullo E, Rubenstein EB. The burdens of cancer therapy: Clinical and economic outcomes of chemotherapy-induced mucositis. Cancer. 2003;98(7):1531-1539. doi:10.1002/cncr.11671

15. Zheng C, Cotrim AP, Sunshine AN, et al. Prevention of radiation-induced oral mucositis after adenoviral vector - Mediated transfer of the keratinocyte growth factor cDNA to mouse submandibular glands. Clin Cancer Res. 2009;15(14):46414648. doi:10.1158/1078-0432.CCR-09-0819 
16. Sá OM de S, Lopes NNF, Alves MTS, Lalla R V, Oliva MLV, Caran EMM. Glycine supplementation reduces the severity of chemotherapy-induced oral mucositis in hamsters. Nat Sci. 2013;05(09):972-978. doi:10.4236/ ns.2013.59118

17. Badiavas E V., Falanga V. Treatment of chronic wounds with bone marrow-derived cells. Arch Dermatol. 2003;139(4):510-516. doi:10.1001/archderm.139.4.510

18. Wu Y, Chen L, Scott PG, Tredget EE. Mesenchymal Stem Cells Enhance Wound Healing Through Differentiation and Angiogenesis. Stem Cells. 2007;25(10):2648-2659. doi:10.1634/stemcells.2007-0226

19. KUDO K, LIU Y, TAKAHASHI K, et al. Transplantation of Mesenchymal Stem Cells to Prevent Radiation-induced Intestinal Injury in Mice. J Radiat Res. 2010;51(1):73-79. doi:10.1269/jrr.09091

20. El-Menoufy H, Aly LAA, Aziz MTA, et al. The role of bone marrow-derived mesenchymal stem cells in treating formocresol induced oral ulcers in dogs. J Oral Pathol Med. 2010;39(4):281-289. doi:10.1111/j.16000714.2009.00819.x

21. De Bari C, Dell'Accio F, Vandenabeele F, Vermeesch JR, Raymackers JM, Luyten FP. Skeletal muscle repair by adult human mesenchymal stem cells from synovial membrane. J Cell Biol. 2003;160(6):909-918. doi:10.1083/ jcb.200212064

22. Zhang Q, Nguyen AL, Shi S, et al. Three-dimensional spheroid culture of human gingiva-derived mesenchymal stem cells enhances mitigation of chemotherapy-induced oral mucositis. Stem Cells Dev. 2012;21(6):937-947. doi:10.1089/scd.2011.0252

23. Aras MH, Sezer U, Erkilic S, Demir T, Dagli SN. Effect of dietary boron on 5-fluorouracil induced oral mucositis in rats. Eur J Dent. 2013;7(3):310-314. doi:10.4103/13057456.115415

24. serry asmaa, Shinaishin S, El Haddad K. Effect of mesenchymal stem cells injection on induced stomatitis in chemotherapy treated rats. J Am Sci. 2017;13(1):41-50.

25. Yazbeck R, Lindsay R, Abbott CA, Benkendorff K, Howarth GS. Combined effects of muricid extract and 5-fluorouracil on intestinal toxicity in rats. Evidence-based Complement Altern Med. 2015;2015. doi:10.1155/2015/170858

26. Fijlstra M, Tissing WJE, Verkade HJ, Rings EHHM. Parenteral feeding during methotrexate-induced gastrointes- tinal mucositis prevents weight loss in the rat. ESPEN J. 2013;8(3). doi:10.1016/j.clnme.2013.03.006

27. Bertolini M, Sobue T, Thompson A, Dongari-Bagtzoglou A. Chemotherapy Induces Oral Mucositis in Mice Without Additional Noxious Stimuli. Transl Oncol. 2017;10(4):612-620. doi:10.1016/j.tranon.2017.05.001

28. González MA, Gonzalez-Rey E, Rico L, Büscher D, Delgado M. Adipose-Derived Mesenchymal Stem Cells Alleviate Experimental Colitis by Inhibiting Inflammatory and Autoimmune Responses. Gastroenterology. 2009;136(3):978-989. doi:10.1053/j.gastro.2008.11.041

29. Toma C, Wagner WR, Bowry S, Schwartz A, Villanueva F. Fate of culture-expanded mesenchymal stem cells in the microvasculature: In vivo observations of cell kinetics. Circ Res. 2009;104(3):398-402. doi:10.1161/CIRCRESAHA.108.187724

30. Vanhoecke B, Bateman E, Mayo B, et al. Dark Agouti rat model of chemotherapy-induced mucositis: Establishment and current state of the art. Exp Biol Med. 2015;240(6):725741. doi:10.1177/1535370215581309

31. Von Bültzingslöwen I, Jontell M, Hurst P, Nannmark U, Kardos T. 5-Fluorouracil induces autophagic degeneration in rat oral keratinocytes. Oral Oncol. 2001;37(6):537-544. doi:10.1016/S1368-8375(01)00009-4

32. Gawish SAAE, Nosseir DA, Omar NM, Sarhan NMR. Histological and ultra structural study of 5-fluorouracilinduced small intestinal mucosal damage in rats. Asian J Cell Biol. 2013;8(1):1-21. doi:10.3923/ajcb.2013.1.21

33. Comeau TB, Epstein JB, Migas C. Taste and smell dysfunction in patients receiving chemotherapy: A review of current knowledge. Support Care Cancer. 2001;9(8):575580. doi:10.1007/s005200100279

34. Chien KR. Lost and found: Cardiac stem cell therapy revisited. J Clin Invest. 2006;116(7):1838-1840. doi:10.1172/ JCI29050

35. Tögel F, Weiss K, Yang Y, Hu Z, Zhang P, Westenfelder C. Vasculotropic, paracrine actions of infused mesenchymal stem cells are important to the recovery from acute kidney injury. Am J Physiol - Ren Physiol. 2007;292(5). doi:10.1152/ajprenal.00339.2006

36. Guo J qi, Gao X, Lin Z jie, et al. BMSCs reduce rat granulosa cell apoptosis induced by cisplatin and perimenopause. BMC Cell Biol. 2013;14(1):18. doi:10.1186/14712121-14-18 
37. Hendijani F. Human mesenchymal stromal cell therapy for prevention and recovery of chemo/radiotherapy adverse reactions. Cytotherapy. 2015;17(5):509-525. doi:10.1016/j. jcyt.2014.10.015

38. Pimorady-Esfahani A, Grounds MD, McMenamin PG. Macrophages and dendritic cells in normal and regenerating murine skeletal muscle. Muscle Nerve. 1997;20(2):158-166. doi:10.1002/(SICI) 10974598(199702)20:2<158::AID-MUS4>3.0.CO;2-B

39. Palmieri B, Tremblay JP, Daniele L. Past, present and future of myoblast transplantation in the treatment of Duchenne muscular dystrophy. Pediatr Transplant. 2010;14(7):813819. doi:10.1111/j.1399-3046.2010.01377.x

40. Coletti D. Chemotherapy-induced muscle wasting: an update. Eur J Transl Myol. 2018;28(2). doi:10.4081/ejtm.2018.7587
41. Koponen JK, Kekarainen T, Heinonen SE, et al. Umbilical cord blood-derived progenitor cells enhance muscle regeneration in mouse hindlimb ischemia model. Mol Ther. 2007;15(12):2172-2177. doi:10.1038/sj.mt.6300302

42. Aboushady, IM 1; Mubarak, R.T. 1,2; El-mougy, S. A. F. 1; Rashed, L.A.3; El-desouky A. The Effect of Transplanted Bone Marrow Stem Cells on the Tongue of Irradiated Rats (Histological and Immunohistochemical study). J Am Sci. 2012;8(11):553-561. http://www.jofamericanscience.org/ journals/am-sci/am0811/084_12116am0811_553_561. pdf. Accessed December 20, 2019.

43. Somaiah C, Kumar A, Sharma R, et al. Mesenchymal stem cells show functional defect and decreased anti-cancer effect after exposure to chemotherapeutic drugs. J Biomed Sci. 2018;25(1):5. doi:10.1186/s12929-018-0407-7 